\title{
Risk Factors and Demographics for Microtia in South America: a Case-Control Analysis
}

\author{
Daniela V. Luquetti ${ }^{1,2}$, Babette S. Saltzman ${ }^{1}$, Jorge Lopez-Camelo ${ }^{3}$, Maria da Graca Dutra ${ }^{4}$, \\ and Eduardo E. Castilla ${ }^{3,4,5}$ \\ ${ }^{1}$ Seattle Children's Hospital, Craniofacial Center, Seattle, WA \\ ${ }^{2}$ University of Washington, Department of Pediatrics, Seattle, WA \\ ${ }^{3}$ ECLAMC (Estudio Colaborativo Latino Americano de Malformaciones Congénitas) at CEMIC \\ (Centro de Educacíon Médica y Investigaciones Clínicas), Buenos Aires, Argentina \\ ${ }^{4}$ ECLAMC at Laboratório de Epidemiologia de Malformações Congênitas, Instituto Oswaldo Cruz, \\ Fundação Oswaldo Cruz, Rio de Janeiro, Brazil \\ 5INAGEMP (Instituto Nacional de Genética Médica Populacional), Rio de Janeiro, RJ, Brazil
}

\begin{abstract}
BACKGROUND-The etiopathogenesis of microtia is still unknown in the majority of the cases, particularly for individuals presenting with isolated microtia. Our aim was to evaluate potential risk factors for this condition using a case-control approach.

METHODS-We analyzed data from 1,194 livebirths with isolated microtia enrolled in the ECLAMC study (Estudio Colaborativo Latino Americano de Malformaciones Congénitas) from 1982 to 2011 and their respective controls. Odds ratios were estimated with conditional logistic regression models along with $95 \%$ confidence intervals for the resulting odds ratio estimates controlling for the effects of potential confounders (sex, maternal age, hospital and year of birth) for an adjusted OR (aOR).

RESULTS-Multiparity was associated with a higher risk of microtia compared to primiparity (aOR 1.5, 95\% CI 1.2-1.8), with women who had eight or more prior pregnancies having the highest risk (aOR 2.8, 95\% CI 1.6-5.2). Women who presented with cold-like symptoms were at higher risk for microtia (aOR 2.2, 95\% CI 1.2-3.9) as well as those that used tobacco or alcohol during pregnancy (aOR 1.7, 95\%CI 1.1-2.5 and aOR 1.4, 95\% CI 0.9-2.1, respectively). The association with alcohol use appeared to be limited to those women who reported binge drinking during pregnancy (aOR 1.4, 95\% 0.7-2.9). Cases from hospitals at low altitude $(<2,500 \mathrm{~m})$ tended to have more severe types of microtia than those from hospitals at high altitude.
\end{abstract}

CONCLUSIONS-These results support the hypothesis that in addition to teratogens other nongenetic risk factors contribute to the occurrence of isolated microtia.

Corresponding author: Daniela V Luquetti, 1900 9th avenue C9S-5, Seattle, WA, USA, Phone: 206-884-5120/Fax: 206-884-1405, daniela.luquetti@seattlechildrens.org. 


\section{Keywords}

microtia; anotia; ear; epidemiology; non-genetic risk factors

\section{INTRODUCTION}

Microtia is a congenital anomaly of the auricle ranging from mild structural abnormalities to complete absence of the ear (Stevenson, 2006). Microtia may occur as an isolated condition ('isolated microtia'), or as part of a spectrum of anomalies or a syndrome. It can occur unilaterally (79-93\%) or bilaterally (Suutarla et al., 2007) and is more likely to affect the right ear ( 60\%; (Suutarla et al., 2007). The pathogenesis of microtia is poorly understood. Case series suggest that teratogens such as gestational exposure to retinoids, alcohol, thalidomide, and the immunosuppressant mycophenolate mofetil, can be associated with microtia (Anderka et al., 2009; Stevenson, 2006). Microtia occurs more often in males and has been associated with multiple gestations (Forrester and Merz, 2005; Shaw et al., 2004); advanced parental age (Castilla and Orioli, 1986; Forrester and Merz, 2005; Harris et al., 1996); higher parity (Castilla and Orioli, 1986; Forrester and Merz, 2005; Harris et al., 1996; Mastroiacovo et al., 1995); low maternal education (Husain et al., 2008; Shaw et al., 2004); low birth weight (Castilla and Orioli, 1986; Forrester and Merz, 2005; Mastroiacovo et al., 1995); maternal illness (Castilla and Orioli, 1986); and high altitude, as defined by higher than 2,500m or 8,200 feet(Castilla et al., 1999). In addition, higher risk for individuals of Asian heritage (Forrester and Merz, 2005; Harris et al., 1996; Shaw et al., 2004), Pacific Islanders (Forrester and Merz, 2005), Native Americans (Aase and Tegtmeier, 1977; Jaffe, 1969; Nelson and Berry, 1984), and individuals of Hispanic descent (Canfield et al., 2009a; Harris et al., 1996; Shaw et al., 2004; Yang et al., 2004) when compared to Caucasians and African Americans has been reported.

Previous risk factor studies of microtia were limited by the following limitations: 1) most are based on relatively small number of cases; 2 ) only a limited number of risk factors have been addressed (for example, only two studies analyzed prenatal risk factors such as maternal acute or chronic illnesses and use of medications, alcohol and tobacco;(Castilla and Orioli, 1986; Mastroiacovo et al., 1995); 3) few distinguished between syndromic and isolated cases (Canfield et al., 2009a; Castilla and Orioli, 1986; Mastroiacovo et al., 1995; Shaw et al., 2004; Zhang et al., 2009), and 4) few involved control groups for comparison (Castilla and Orioli, 1986; Mastroiacovo et al., 1995; Van Bennekom et al., 2013; Zhang et al., 2009). The previous study in the South America population also used the ECLAMC network data; however that dataset consisted of isolated and syndromic cases of microtia from 1967 to 1977 during which the network had fewer hospitals participating. The current analysis used more recent data (1982-2011) and includes other risk factors not investigated in the prior study.

The objective of this study was to identify potential risk factors associated with microtia using a case-control approach. We hypothesized that the occurrence of microtia is associated with specific risk factors, including exposures during the mother's pregnancy and race/ 
ethnicity. Identification of potential modifiable risk factors for microtia will provide new insights into its etiology and prevention strategies.

\section{METHODS}

\section{Study population}

ECLAMC (Estudio Colaborativo Latino Americano de Malformaciones Congénitas) is a research group dedicated to the study of the epidemiology and etiology of birth defects using a hospital-based case-control study in South America. ECLAMC's methodology has been described in detail elsewhere.(Castilla and Orioli, 2004) Briefly, trained physicians conduct active ascertainment of newborns with birth defects (cases) through daily physical examination of all births at participating hospitals; birth defects are described in detail according to the ECLAMC manual of procedures. Each identified case is matched to a control as follows: they are the subsequent infant born of the same sex, born sequentially after the case in the same hospital; with no identified birth defect whose mothers agree to participate (approximately $95 \%$ of potential controls agree to participate). The mothers of cases and controls are interviewed during the birth hospitalization, using a standardized ECLAMC form; a questionnaire designed to collect the newborn physical examination, prenatal history, demographic information, and family history of birth defects.

We included all live-births coded in ECLAMC database as having isolated microtia born from 1982 through 2011. In order to minimize the potential heterogeneity of the case group we did not include microtia cases with additional unrelated congenital anomalies; this heterogeneity might obscure risk factors involved specifically in the development of isolated microtia. Cases with microtia were considered isolated if they did not present any other malformation or if they only presented selected minor congenital anomalies. (For list of anomalies considered minor for the purpose of this study, please see appendix 1).

In ECLAMC, controls are not assigned to stillbirths, therefore stillborn cases were excluded from this analysis, they constituted $1.1 \%(\mathrm{n}=13)$ of all isolated microtia cases.

\section{Covariates and potential risk factors}

We included the following factors as part of cases' phenotypic description: laterality, severity (microtia: I-IV, according to Marx classification), birth weight, and sex. We explored the following exposures as potential risk factors: acute and chronic maternal illness; plurality, smoking; ingestion of alcohol, medications, or drugs; parity; parental ages, occupation and education level; consanguinity; family history, and self-described race/ ethnicity. Information on some of these exposures were only collected after 2002, this is indicated in the tables.

\section{Statistical Analysis}

We used standard methods for the analysis of case-control data. Although controls were individually matched to cases, in order to perform subgroup analyses and maximize our ability to detect associations between rare exposures and microtia, we fit logistic regression models to estimate associations between proposed risk factors and microtia risk along with 
95\% confidence intervals for the resulting odds ratio (OR) estimates. We individually assessed the risk of microtia with exposures of interest, while controlling for potential confounders. Control for confounding was carried out using a set of covariates determined a priori base on a literature review; we adjusted models for the matching variables (sex, hospital and year of birth) as well as maternal age to calculate an adjusted OR (aOR). We only reported ORs for exposures that had at least five exposed cases. We performed subgroup analysis including only those cases and controls without a family history of microtia.

\section{RESULTS}

There were a total of 1,194 cases of isolated microtia; of those $56.6 \%$ were males. Microtia was unilateral in $82.0 \%$ of cases, and in $65.6 \%$ of those the right side was affected. Cases and controls did not differ substantially with respect to birth weight, gestational age, plurality, maternal age, maternal education, paternal occupation, parental consanguinity and race/ethnicity (Tables 1 and 2).

Multiparous women had a higher risk of microtia in their offspring compared to primiparous women, this association was stronger among women who had eight or more prior pregnancies (aOR 1.5, 95\% CI 1.2-1.8 and aOR 2.8, 95\% CI 1.6-5.2, respectively); these findings were similar across groups defined by interpregnancy interval. Women who smoked during pregnancy had a $70 \%$ higher risk of having a child with microtia relative to non-smokers (95\%CI 1.1-2.6); the risk was similar for those who smoked fewer than 10 or 10 or more cigarettes per day. While women who consumed alcohol during pregnancy also presented a higher risk of having a child with microtia (aOR 1.4, 95\% CI 0.9-2.1), this association appeared to be limited to those women who reported binge drinking at least once during pregnancy (aOR 1.4, 95\% 0.7-2.9), however, these observations may have been due to chance. Women that were employed outside the home had a $30 \%$ higher risk of having offspring with microtia than women who reported being housewives (95\% CI 1.1-1.5; Table 2).

Diagnosis of any acute or chronic disease at anytime during pregnancy was associated with an elevated risk of microtia (aOR 1.4, 95\% CI 1.2-1.6 and aOR 1.3, 95\%CI 1.0-1.7, respectively; Table 2). When we evaluated risk of microtia by specific conditions reported during the first trimester; we found that report of cold-like symptoms was associated with risk of microtia (aOR 2.2, 95\% CI 1.2-3.9). We also found women who reported nausea, asthma or respiratory infections had a 40-270\% higher risk of having a child with microtia, however these estimates were based on cells with fewer than 5 individuals and so were statistically imprecise (Table 3).

The reported use of any medication during the first trimester of pregnancy was associated with a higher risk for having a child with microtia (aOR 1.5, 95\% CI 1.3-1.8; Table 3). Specific medications that were associated with microtia were: analgesics, antiemetics, antibiotics antihypertensives, antispasmodics, drugs for functional bowel disorders and hormones. While all classes of analgesics were associated with a 2-fold or higher microtia risk, acetaminophen was the most frequently reported and the only that reached statistical 
significance for an association (aOR 2.1, 95\% CI 1.2-3.8; Table 4). The combined effect of cold symptoms and acetaminophen was not higher than that we would expect from each of their independent effects; the association between acetaminophen and microtia persisted when we adjusted for possible confounding by cold symptoms.

Microtia characterized by Marx as type I was most common (39.7\%), followed by types 2, 3 and 4 (35.1, 17.8, and 3.4\%, respectively). Cases from hospitals at low altitude $(<2,500 \mathrm{~m})$ tended to have more severe types of microtia than those from hospitals at high altitude (Table 5).

One hundred cases $(8.4 \%)$ had at least one relative affected with microtia, compared to only 6 controls $(0.5 \%)$ who had any relatives with microtia (aOR 18.1, 95\%CI 7.9-41.4; data not shown). When we restricted our analyses to those cases with no family history of microtia, no substantial differences in the associations studied were observed.

\section{DISCUSSION}

Although several published reports have attempted to identify risk factors for microtia, only four of these have been case-control studies (Table 6) (Castilla and Orioli, 1986; Mastroiacovo et al., 1995; Paput et al., 2011a; Paput et al., 2011b; Van Bennekom et al., 2013). While they also recruited controls through population and hospital birth cohorts, these ranged in size from 172 to 411 cases, and control participation rates were reported for only one study (Van Bennekom et al., 2013) retaining the possibility that bias may have accounted for some of the associations which were reported. Use of ECLAMC data presented a unique opportunity to evaluate the association between microtia and various risk factors since it contains data on 1,194 cases of isolated microtia. Since approximately $95 \%$ of the controls agreed to participate, the prevalence of selection bias that may result was minimized. This evaluation within this well established south-American study population allowed us to evaluate exposures that may be specific for this high-risk population because the geography, ancestry, and culture differ from those of populations previously described in literature.

Our cases presented similar phenotypic characteristics to the ones described in previous studies of microtia, such as higher proportion of males (56.6\%) than expected in the general population at birth (51.5\%); for unilateral cases the right side was more commonly affected than the left side, and in relation to severity of microtia, anotia (type 4) accounted for only a small proportion of cases. However, while an association has been found between low birth weight and microtia in three previous studies, including one using ECLAMC data from 1967-1977 (Castilla and Orioli, 1986; Forrester and Merz, 2005; Mastroiacovo et al., 1995), we did not find a difference between the reported birth weights of cases and controls in our study, this could be due to our adjustment in the analysis for hospital. Adjustment for birth hospital may serve as a proxy for regional birth weight differences related to ethnicity, nutrition, etc.

Our findings of a modest association between multiple births and microtia are consistent with those reported previously (Forrester and Merz, 2005; Shaw et al., 2004); similarly, an 
association has been established between microtia and low maternal education (Canfield et al., 2009a; Harris et al., 1996; Shaw et al., 2004) and we also found a modestly elevated risk among women in the lowest education stratum.

We observed a higher risk of microtia among multiparous women, this increasing risk was seen among women giving birth to their second (and subsequent) child, and doubled after the $8^{\text {th }}$ pregnancy. Multiparity as a risk factor for microtia has been reported in previous studies; however a modestly increased risk (10\%) was seen only in the stratum of highest parity, defined in these studies as four or more pregnancies (Harris et al., 1996; Shaw et al., 2004). The hypothesis given by these authors is a correlation between multiparity and short interpregnancy intervals ( $<6$ months) which may be associated with an increased risk of birth defects, possibly because of nutrient depletion (Grisaru-Granovsky et al., 2009). In order to rule out this possibility, we repeated analyses while looking simultaneously at parity and interpregnancy interval, and did not find that either variable had a modifying effect on the association between the other and microtia risk. Contrary to our findings, Mastroiacovo et al. (1995) reported 55.3\% of cases' mothers were primiparous compared to 50.5\% of controls' mothers $(\mathrm{p}=0.34)$ whereas Duong et al (2012) found that primiparous women were at a slightly higher risk for microtia (aORs: $1.06,95 \% \mathrm{CI}$ : $0.82-1.37$ ) than multiparous women. Studies of other birth defects have inconsistently observed a modest to null association between multiparity and oral clefts and neural tube defects (Canfield et al., 2009b; Duong et al., 2012; Hashmi et al., 2005; Vieira, 2004; Vieira and Orioli, 2002).

We did not find any association with older maternal or paternal age as seen in previous studies. In population-based descriptive studies in Texas (Canfield et al., 2009a) and in Hawaii (Forrester and Merz, 2005), a higher birth prevalence with increasing maternal age was observed; likewise, Harris et al (1996) found an OR 1.92 (95\% CI:0.96-3.85) for mothers aged 35 years or older, however these findings might be the result of unidentified chromosomal anomalies as they included cases associated with other birth defects in the analysis. In the previous study in South America, paternal age was significantly higher in cases $(30.2 \pm 7.8)$ than in controls $(27.6 \pm 5.8)$.

Although Native American ancestry did show a slighter higher risk, we did not find an association to race/ethnicity; this was not unexpected since cases and controls were matched for hospital therefore there was a potential for overmatching of race/ethnicity. In studies performed in the US population, Hispanics have been described as having higher risk for microtia (Canfield et al., 2009a; Luquetti et al., 2011; Ramadhani et al., 2009; Shaw et al., 2004); however it is not clear what aspect of the ancestry admixture among the U.S. Hispanic population this is related to.

We were unable to evaluate altitude in relation to the occurrence of microtia in these casecontrol analysis because of the overmatching between cases and controls in relation to these potential risk factors. However, we compared severity of microtia between cases from hospitals at low and high altitudes and observed a tendency to more severe microtia in cases from low altitude hospitals. Previous studies, one of them using ECLAMC data, have shown a higher prevalence of microtia in population living at high altitude (Castilla et al., 1999; González-Andrade et al., 2010). It is important to highlight that in South America, altitude 
and ancestry are strongly correlated; populations at high altitude have a much higher proportion of Native American and a much lower of African ancestry when compared to the populations living at a low altitude. Thus, it is still unclear if altitude is a risk factor, due to chronic exposure to hypoxia or different diet habits, or if there is a genetic susceptibility related to ancestry or if there is a combined effect of both altitude and ancestry.

The maternal illness during the prenatal period most substantially associated with microtia was a history of cold-like symptoms. Fewer than five case mothers reported having maternal diabetes in the first trimester, a condition found to be associated with microtia in several studies (Correa et al., 2008; Mastroiacovo et al., 1995; Wang et al., 2002). Although Van Bennekom et al. (2013) observed that maternal hypertension was more frequently reported among mothers of cases of microtia than controls (OR, 1.6; 95\% CI, 1.0-2.5), we did not find an association with this condition.

We observed an increased risk of microtia among women who used any medication during the first trimester of pregnancy. The analysis by specific group of drugs showed a higher risk of microtia among mothers who used analgesics, antibiotics, antispasmodics and varying combinations of progestogens and estrogens. Among analgesics, use of acetaminophen was the most commonly reported and the only one that reached statistical significance. However, multiple previous studies have evaluated the effect of acetaminophen use during the first trimester and overall no association was found with any birth defects using population based birth cohorts (Aselton et al., 1985; Jick et al., 1981; Rebordosa et al., 2008; Thulstrup et al., 1999). The positive association observed in our study could be due to exposure misclassification (timing of use) or recall bias, particularly for a common medication such as acetaminophen. Feldkamp et al (2010) reported a decreased risk when acetaminophen was used during a febrile condition in the mother for some birth defects, including microtia. Our analysis stratifying by maternal fever or cold-like symptoms suggested that the association present in these data is not the result of confounding (and spurious presence) by colds or cold like symptoms during the pregnancy since the association persisted after adjustment and was similar within groups defined by presence or absence of cold like symptoms during pregnancy.

Contrary to our findings, a previous study by the National Birth Defects Prevention Study (NBDPS) on antibiotics and risk of selected birth defects found no association with microtia (aOR 0.9, 95\%CI 0.6-1.4) (Crider et al., 2009). A notable difference between our study and the NBDPS includes timing of maternal interview (at birth vs. 6 months to 2 years) which could have lead to recall bias in the NBDPS data, i.e., with more time between birth and the study interview, the mothers of the cases could potentially reevaluate their exposures more intensively than controls. However, it was not possible to determine what aspect of antibiotic use was associated with the higher risk; the actual use of the antibiotic medications or the infections that lead to their use. In a study by Van Bennekon (Van Bennekom et al., 2013) no association with vasoactive drugs (NSAIDs, decongestants, bronchodilators, antihypertensive) use in the first trimester and microtia was found. We did observe an association with use of antihypertensives; however this was based on a small number of exposed mothers and therefore could be a spurious finding. 
We were unable to assess the association between maternal use of medications which have been strongly associated with microtia such as retinoids, mycophenolate mofetil, thalidomide, and carbimazole/methimazole (Anderka et al., 2009; Carey et al., 2006; Gripp et al., 2011), since no use was reported by mothers of cases or controls in our study; it is encouraging that these medications appear not to be used by pregnant women in the population being studied.

We observed an association both with use of tobacco and alcohol during pregnancy. Smoking and alcohol use was not previously reported to be associated with microtia in the two case-control studies that looked specifically at these risk factors for isolated microtia, however both studies had relatively small sample sizes of 114 (Mastroiacovo et al., 1995) and 296 cases (Van Bennekom et al., 2013) compared to ours. In Utah, (Srisukhumbowornchai et al., 2012) a study on smoking and birth defects showed a weak association between maternal smoking at any time during pregnancy and microtia (aOR $1.08,95 \% \mathrm{CI} 0.35-3.41)$. In a study evaluating the relation between paternal smoking and birth defects, there appeared to be an elevated risk of offspring with microtia among men who smoked (Zhang et al., 1992). Nicotine is believed to cause oxidative stress that could be related to neural crest disturbance, in a similar manner as hyperglycemia. Likewise, alcohol has been involved in neural crest cell migration impairment.

Our findings should be interpreted in light of the study limitations and strengths. Data quality must always be acknowledged as a possible limitation. However, the diagnosis of the birth defect, in this case, microtia, is made by trained ECLAMC physicians and described following a standardized protocol. Case ascertainment occurs by active examination of all births in participating hospitals which reduces potential case selection bias due to incomplete ascertainment. Assessment of exposure is based on a questionnaire administered to the mothers by trained interviewers. Following ECLAMC protocol, the maternal interview occurs in the first three days after birth reducing recall bias. Coding was performed centrally until 2005 and since then through an automated system that is reviewed periodically for inconsistencies.

In a recent analysis using ECLAMC data, Poletta et al (2012) found 29 birth defects were significantly associated with acetaminophen use when using healthy live-births as controls as in the current study. They compared their data to the study on acetaminophen by Feldkamp et al (2010) that showed no association to any of the 50 major birth defects studied, however it must be acknowledged that the proportion of exposed population in that study was much higher than in ECLAMC ( 45\% compared to 3\%). Using additional set of sick controls and case-only approach, they suggested that this was presumably caused by bias resulting from differential misclassification that decreased with the increased proportion of exposed controls. This same bias could also explain the difference observed in the present study for acetaminophen and other exposures, particularly those with low proportion of exposed controls.

Smoking, alcohol and recreational drugs may have been underreported because of social stigma related to their use, particularly during pregnancy; furthermore the degree of underreporting may vary for cases and controls. We also acknowledge that even with the 
relatively large sample size, there were small numbers of exposed cases for several of the exposures investigated, thus some of these estimates are unstable. Questions for use of medications and maternal illnesses are open-ended, which may lead to potential loss of information and recall bias from case-mothers. Control for confounding was based on multivariable regression analyses using a set of covariates determined a priori base on a literature review; there was little difference between crude and adjusted ORs, suggesting that the covariates had small effect on estimates. However it is still possible that residual confounding or effect modification may have influenced some of our findings, particularly those related to race/ethnicity and altitude.

This large sample size and relatively large exposure rates enabled us to detect the presence of even relatively weak associations. We have identified potential risk factors (multiparity, maternal use of tobacco, some medications and cold-like symptoms during the $1^{\text {st }}$ trimester) of which the few previous studies had conflicting results adding to the evidence that they are very likely implicated in the cause of microtia. Some, such as use of tobacco and the use of medications are modifiable risk factors, and campaigns for prevention of birth defects might be reinforced using these data. Further studies on the interrelation between genetic and nongenetic risk factors and their causal pathways will enable us to understand better the etiology of microtia.

\section{Acknowledgments}

Grant information and grant numbers: This work was supported by the National Institute on Deafness and Other Communication Disorders at the National Institutes of Health (grant number K99DC011282).

\section{References}

Aase JM, Tegtmeier RE. Microtia in New Mexico: evidence for multifactorial causation. Birth defects original article series. 1977; 13(3A):113-116. [PubMed: 884237]

Anderka MT, Lin AE, Abuelo DN, Mitchell AA, Rasmussen SA. Reviewing the evidence for mycophenolate mofetil as a new teratogen: case report and review of the literature. American journal of medical genetics. 2009; 149A(6):1241-1248. [PubMed: 19441125]

Aselton P, Jick H, Milunsky A, Hunter JR, Stergachis A. First-trimester drug use and congenital disorders. Obstetrics and gynecology. 1985; 65(4):451-455. [PubMed: 3982720]

Canfield MA, Langlois PH, Nguyen LM, Scheuerle AE. Epidemiologic features and clinical subgroups of anotia/microtia in Texas. Birth defects research. 2009a; 85:905-913. [PubMed: 19760683]

Canfield MA, Marengo L, Ramadhani TA, Suarez L, Brender JD, Scheuerle A. The prevalence and predictors of anencephaly and spina bifida in Texas. Paediatr Perinat Epidemiol. 2009b; 23(1):4150. [PubMed: 19228313]

Carey, JC.; Park, AH.; Muntz, HR. External Ear. In: Stevenson, RE., editor. Human malformations and related anomalies. Oxford; New York: Oxford University Press; 2006. p. 329-338.

Castilla EE, Lopez-Camelo JS, Campana H. Altitude as a risk factor for congenital anomalies. American journal of medical genetics. 1999; 86(1):9-14. [PubMed: 10440822]

Castilla EE, Orioli IM. Prevalence rates of microtia in South America. International journal of epidemiology. 1986; 15(3):364-368. [PubMed: 3771073]

Castilla EE, Orioli IM. ECLAMC: the Latin-American collaborative study of congenital malformations. Community genetics. 2004; 7(2-3):76-94. [PubMed: 15539822]

Correa A, Gilboa SM, Besser LM, Botto LD, Moore CA, Hobbs CA, Cleves MA, Riehle-Colarusso TJ, Waller DK, Reece EA. Diabetes mellitus and birth defects. Am J Obstet Gynecol. 2008; 199(3):237, e231-239. [PubMed: 18674752] 
Crider KS, Cleves MA, Reefhuis J, Berry RJ, Hobbs CA, Hu DJ. Antibacterial medication use during pregnancy and risk of birth defects: National Birth Defects Prevention Study. Arch Pediatr Adolesc Med. 2009; 163(11):978-985. [PubMed: 19884587]

Duong HT, Hoyt AT, Carmichael SL, Gilboa SM, Canfield MA, Case A, McNeese ML, Waller DK. Is maternal parity an independent risk factor for birth defects? Birth defects research. 2012; 94(4): 230-236. [PubMed: 22371332]

Feldkamp ML, Meyer RE, Krikov S, Botto LD. Acetaminophen use in pregnancy and risk of birth defects: findings from the National Birth Defects Prevention Study. Obstetrics and gynecology. 2010; 115(1):109-115. [PubMed: 20027042]

Forrester MB, Merz RD. Descriptive epidemiology of anotia and microtia, Hawaii, 1986-2002. Congenital anomalies. 2005; 45(4):119-124. [PubMed: 16359491]

González-Andrade F, López-Pulles R, Espín VH, Paz-y-Miño C. High altitude and microtia in Ecuadorian patients. Journal of Neonatal-Perinatal Medicine. 2010; 3(2):109-116.

Gripp KW, Kuryan R, Schnur RE, Kothawala M, Davey LR, Antunes MJ, Reichard KW, Schneider A, Hall BD. Grade 1 microtia, wide anterior fontanel and novel type tracheo-esophageal fistula in methimazole embryopathy. American journal of medical genetics. 2011; 155A(3):526-533. [PubMed: 21344626]

Grisaru-Granovsky S, Gordon ES, Haklai Z, Samueloff A, Schimmel MM. Effect of interpregnancy interval on adverse perinatal outcomes--a national study. Contraception. 2009; 80(6):512-518. [PubMed: 19913144]

Harris J, Kallen B, Robert E. The epidemiology of anotia and microtia. Journal of medical genetics. 1996; 33(10):809-813. [PubMed: 8933331]

Hashmi SS, Waller DK, Langlois P, Canfield M, Hecht JT. Prevalence of nonsyndromic oral clefts in Texas: 1995-1999. American journal of medical genetics. 2005; 134(4):368-372. [PubMed: 15779018]

Husain T, Langlois PH, Sever LE, Gambello MJ. Descriptive epidemiologic features shared by birth defects thought to be related to vascular disruption in Texas, 1996-2002. Birth defects research. 2008; 82(6):435-440. [PubMed: 18383510]

Jaffe BF. Incidence of ear diseases in Navajo Indians. The Laryngoscope. 1969; 79(12):2126. [PubMed: 5362681]

Jick H, Holmes LB, Hunter JR, Madsen S, Stergachis A. First-trimester drug use and congenital disorders. JAMA. 1981; 246(4):343-346. [PubMed: 7241780]

Luquetti DV, Leoncini E, Mastroiacovo P. Microtia-anotia: a global review of prevalence rates. Birth defects research. 2011; 91(9):813-822. [PubMed: 21656661]

Mastroiacovo P, Corchia C, Botto LD, Lanni R, Zampino G, Fusco D. Epidemiology and genetics of microtia-anotia: a registry based study on over one million births. Journal of medical genetics. 1995; 32(6):453-457. [PubMed: 7666397]

Nelson SM, Berry RI. Ear disease and hearing loss among Navajo children--a mass survey. The Laryngoscope. 1984; 94(3):316-323. [PubMed: 6700346]

Paput L, Banhidy F, Czeizel AE. Association of drug treatments in pregnant women with the risk of external ear congenital abnormalities in their offspring: a population-based case-control study. Congenital anomalies. 2011a; 51(3):126-137. [PubMed: 21848996]

Paput L, Czeizel AE, Banhidy F. Maternal diseases and risk of isolated ear abnormalities in their children. Cent Eur J Public Health. 2011b; 19(3):170-176. [PubMed: 22026295]

Poletta FA, Lopez Camelo JS, Gili JA, Leoncini E, Castilla EE, Mastroiacovo P. Methodological approaches to evaluate teratogenic risk using birth defect registries: advantages and disadvantages. PloS one. 2012; 7(10):e46626. [PubMed: 23056376]

Ramadhani T, Short V, Canfield MA, Waller DK, Correa A, Royle M, Scheuerle A. Are birth defects among Hispanics related to maternal nativity or number of years lived in the United States? Birth defects research. 2009; 85(9):755-763. [PubMed: 19350653]

Rebordosa C, Kogevinas M, Horvath-Puho E, Norgard B, Morales M, Czeizel AE, Vilstrup H, Sorensen HT, Olsen J. Acetaminophen use during pregnancy: effects on risk for congenital abnormalities. Am J Obstet Gynecol. 2008; 198(2):178 e171-177. [PubMed: 18226618] 
Shaw GM, Carmichael SL, Kaidarova Z, Harris JA. Epidemiologic characteristics of anotia and microtia in California, 1989-1997. Birth defects research. 2004; 70(7):472-475. [PubMed: 15259037]

Srisukhumbowornchai S, Krikov S, Feldkamp ML. Self-reported maternal smoking during pregnancy by source in Utah, 2003-2007. Birth defects research. 2012; 94(12):996-1003. [PubMed: 22821801]

Stevenson, RE. Human malformations and related anomalies. Oxford; New York: Oxford University Press; 2006.

Suutarla S, Rautio J, Ritvanen A, Ala-Mello S, Jero J, Klockars T. Microtia in Finland: comparison of characteristics in different populations. International journal of pediatric otorhinolaryngology. 2007; 71(8):1211-1217. [PubMed: 17548114]

Thulstrup AM, Sorensen HT, Nielsen GL, Andersen L, Barrett D, Vilstrup H, Olsen J. Fetal growth and adverse birth outcomes in women receiving prescriptions for acetaminophen during pregnancy. EuroMap Study Group. Am J Perinatol. 1999; 16(7):321-326. [PubMed: 10614698]

Van Bennekom CM, Mitchell AA, Moore CA, Werler MM. Vasoactive exposures during pregnancy and risk of microtia. Birth defects research. 2013; 97(1):53-59. [PubMed: 23180593]

Vieira AR. Birth order and neural tube defects: a reappraisal. J Neurol Sci. 2004; 217(1):65-72. [PubMed: 14675612]

Vieira AR, Orioli IM. Birth order and oral clefts: a meta analysis. Teratology. 2002; 66(5):209-216. [PubMed: 12397628]

Wang R, Martinez-Frias ML, Graham JM Jr. Infants of diabetic mothers are at increased risk for the oculo-auriculo-vertebral sequence: A case-based and case-control approach. The Journal of pediatrics. 2002; 141(5):611-617. [PubMed: 12410187]

Yang J, Carmichael SL, Kaidarova Z, Shaw GM. Risks of selected congenital malformations among offspring of mixed race-ethnicity. Birth defects research. 2004; 70(10):820-824. [PubMed: 15390318]

Zhang J, Savitz DA, Schwingl PJ, Cai WW. A case-control study of paternal smoking and birth defects. International journal of epidemiology. 1992; 21(2):273-278. [PubMed: 1428480]

Zhang QG, Zhang J, Yu P, Shen H. Environmental and Genetic Factors Associated with Congenital Microtia: A Case-Control Study in Jiangsu, China, 2004 to 2007. Plastic and reconstructive surgery. 2009; 124(4):1157-1164. [PubMed: 19935299] 


\section{Table 1}

Demographic Characteristics of Controls and Cases with Isolated Microtia in ECLAMC, Period: 1982-2011.

\begin{tabular}{lrr}
\hline & $\begin{array}{r}\text { Controls n=1,194 } \\
\text { Mean (SD) }\end{array}$ & $\begin{array}{r}\text { Isolated microtia n=1,194 } \\
\text { Mean (SD) }\end{array}$ \\
\hline Birth weight & $3181.7(560.1)$ & $3163.0(613.1)$ \\
Gestational Age (weeks) & $38.9(2.2)$ & $39.0(2.4)$ \\
Parity & $2.4(1.8)$ & $2.7(2.0)$ \\
Maternal age & $25.7(6.6)$ & $26.1(6.4)$ \\
Paternal age & $29.1(7.8)$ & $29.5(7.5)$ \\
\hline
\end{tabular}

SD: standard deviation 


\section{Table 2}

Adjusted Odds Ratio for the Association between Isolated Microtia and Selected Risk Factors, in ECLAMC, Period: 1982-2011.

\begin{tabular}{|c|c|c|c|}
\hline & Controls $(n=1,194)$ & Isolated microtia $(\mathrm{n}=1,194)$ & \\
\hline & No. $(\%)$ & No. $(\%)$ & $\operatorname{aOR}(95 \% \mathrm{CI})^{A}$ \\
\hline Multiple births ( $\geq 2$ ) & $18(1.5)$ & $23(1.9)$ & $1.2(0.6-2.3)$ \\
\hline \multicolumn{4}{|l|}{ Parity } \\
\hline Primipara & $455(40.4)$ & $364(32.0)$ & $1.00(\mathrm{ref})$ \\
\hline 2-7 pregnancies & $653(57.9)$ & $734(64.6)$ & $1.5(1.2-1.8)$ \\
\hline$\geq 8$ pregnancies & $19(1.7)$ & $39(3.4)$ & $2.8(1.6-5.2)$ \\
\hline \multicolumn{4}{|l|}{ Number of cigarettes (daily) ${ }^{B}$} \\
\hline 0 & $251(83.4)$ & $234(76.2)$ & 1.00 (ref) \\
\hline$\geq 1$ & $50(16.6)$ & $73(23.8)$ & $1.7(1.1-2.6)$ \\
\hline Reported using alcohol during pregnancy $B$ & $55(18.6)$ & $73(24.2)$ & $1.4(0.9-2.1)$ \\
\hline \multicolumn{4}{|l|}{ Reported binge drinking $B$} \\
\hline Never drank & $238(82.1)$ & $213(78.0)$ & $1.00(\mathrm{ref})$ \\
\hline Drank, but never binged & $39(13.4)$ & $42(15.4)$ & $1.2(0.7-1.9)$ \\
\hline Engaged in binge drinking $(\geq 1)$ & $13(4.5)$ & $18(6.6)$ & $1.4(0.7-3.1)$ \\
\hline Reported using illegal drugs during pregnancy $B$ & $7(2.6)$ & $7(2.6)$ & $1.0(0.3-2.9)$ \\
\hline Reported using medications during $1^{\text {st }}$ trimester of pregnancy & $364(31.0)$ & $532(40.2)$ & $1.5(1.3-1.8)$ \\
\hline Acute diseases during pregnancy & $371(31.7)$ & $455(38.6)$ & $1.4(1.2-1.6)$ \\
\hline Chronic diseases & $101(8.6)$ & $131(11.2)$ & $1.3(1.0-1.7)$ \\
\hline \multicolumn{4}{|l|}{ Maternal years of school } \\
\hline$>8$ years & $723(60.6)$ & $694(58.1)$ & 1.00 (ref) \\
\hline$<8$ years & $471(39.4)$ & $500(41.9)$ & $1.1(0.9-1.3)$ \\
\hline \multicolumn{4}{|l|}{ Paternal years of school } \\
\hline$>8$ years & $760(63.7)$ & $715(59.9)$ & 1.00 (ref) \\
\hline$<8$ years & $434(36.3)$ & $479(40.1)$ & $1.2(1.0-1.4)$ \\
\hline \multicolumn{4}{|l|}{ Maternal occupation ${ }^{B}$} \\
\hline Housewife & $813(69.8)$ & $747(64.2)$ & $1.00(\mathrm{ref})$ \\
\hline Employed outside the home & $352(30.2)$ & $417(35.8)$ & $1.3(1.1-1.5)$ \\
\hline \multicolumn{4}{|l|}{ Paternal occupation } \\
\hline Blue collar & $555(53.2)$ & $568(53.0)$ & $1.00(\mathrm{ref})$ \\
\hline White collar & $489(46.8)$ & $503(47.0)$ & $1.0(0.8-1.2)$ \\
\hline Parental consanguinity & $12(1.0)$ & $16(1.4)$ & $1.3(0.6-2.7)$ \\
\hline \multicolumn{4}{|l|}{ Race/Ethnicity } \\
\hline Native American (any) & $925(77.5)$ & $946(79.2)$ & $1.1(0.9-1.3)$ \\
\hline White (any) & $127(10.6)$ & $112(9.4)$ & $0.9(0.7-1.1)$ \\
\hline Black (any) & $83(7.0)$ & $81(6.8)$ & $1.0(0.7-1.3)$ \\
\hline
\end{tabular}


${ }^{B}$ Data was collected from 2002 onwards. We also separately fewer than- and more than- 10 cigarettes/day as separate categories and found similar risks for each. 


\section{Table 3}

Selected Maternal Acute and Chronic Diseases during the $1^{\text {st }}$ Trimester of Pregnancy in ECLAMC, Period: 1982-2011.

\begin{tabular}{lrrr}
\hline & Controls (n=962) & Isolated microtia (n=932) & \\
& No. $(\%)$ & No. $(\%)$ & aOR (95\% CI) $\boldsymbol{A}$ \\
\hline Nausea/Vomiting & $20(2.3)$ & $27(3.3)$ & $1.4(0.8-2.6)$ \\
Asthma & $4(0.5)$ & $10(1.2)$ & $2.7(0.8-8.6)$ \\
Cold-like symptoms & $17(1.9)$ & $35(4.2)$ & $2.2(1.2-3.9)$ \\
Hypertension & $7(0.8)$ & $6(0.7)$ & $0.9(0.3-2.8)$ \\
Respiratory infection & $3(0.3)$ & $7(0.9)$ & $2.5(0.6-9.7)$ \\
Urinary infection & $43(4.8)$ & $41(4.9)$ & $1.0(0.7-1.6)$ \\
\hline
\end{tabular}

aOR: Adjusted Odds Ratio

${ }^{A}$ Adjusted by sex, maternal age, hospital and year of birth. 
Table 4

Selected Medications Used by Mothers during $1^{\text {st }}$ Trimester of Pregnancy in ECLAMC, Period: 1982-2011.

\begin{tabular}{lrrr}
\hline & Controls (n=764) & Isolated microtia (n=777) \\
& No. (\%) & No. (\%) & aOR (95\% CI) ${ }^{\boldsymbol{A}}$ \\
\hline Analgesics $B$ & $31(5.1)$ & $59(10.4)$ & $2.2(1.4-3.4)$ \\
Non-steroidal antiinflammatories & $6(1.0)$ & $12(2.3)$ & $2.1(0.8-5.7)$ \\
Antacids & $10(1.7)$ & $8(1.6)$ & $0.9(0.4-2.3)$ \\
Antibiotics $C$ & $39(6.3)$ & $58(10.3)$ & $1.6(1.1-2.5)$ \\
Antiemetics & $2(0.3)$ & $8(1.6)$ & $4.5(1.0-21.4)$ \\
Antihypertensives $D$ & $3(0.5)$ & $9(1.7)$ & $3.6(1.0-13.7)$ \\
Antispasmodics & $8(1.4)$ & $19(3.6)$ & $2.8(1.2-6.5)$ \\
Anxiolytics & $1(0.2)$ & $6(1.2)$ & $7.4(0.9-62.2)$ \\
Drugs for Functional bowels diseases & $7(1.2)$ & $21(4.0)$ & $3.6(1.5-8.5)$ \\
Progestogens/estrogens combinations & $4(0.7)$ & $20(3.8)$ & $6.1(2.1-18.1)$ \\
Vitamins and minerals & $122(17.4)$ & $126(19.9)$ & $1.2(0.9-1.6)$ \\
\hline
\end{tabular}

aOR: Adjusted Odds Ratio

${ }^{A}$ Adjusted by sex, maternal age, hospital and year of birth.

${ }^{B}$ Acetylsalicylic acid, acetaminophen, metamizole, the more frequently reported analgesics presented similar ORs

$C_{\text {Amoxicillin, ampicillin, cephalexin, the more frequently reported antibacterials presented similar ORs }}$

$D_{\text {Metildopa the more frequently reported antihypertensive presented similar OR }}$ 
Table 5

Type of microtia in low and high altitude in ECLAMC, Period: 1997-2011 ${ }^{A}$

\begin{tabular}{lrrr}
\hline & Low Altitude $\left(<\mathbf{2 , 5 0 0 ~} \mathbf{~}^{\boldsymbol{B}}\right)$ & High Altitude $\left(>\mathbf{2 , 5 0 0} \mathbf{~ m}{ }^{\boldsymbol{B}}\right)$ & Total cases \\
& $\mathbf{n = 5 3 8}$ & $\mathbf{n = 2 8 3}$ & $\mathbf{n = 8 2 1}$ \\
Type of microtia (Marx classification) & $\mathbf{\%}$ & $\mathbf{\%}$ & $\mathbf{\%}$ \\
\hline Type 1 & 41.4 & 41.3 & 39.7 \\
Type 2 & 33.5 & 42.4 & 35.1 \\
Type 3 & 20.3 & 15.2 & 17.8 \\
Type 4 & 4.8 & 1.1 & 3.4 \\
\hline$A_{\text {Type of microtia was only recorded from 1997 onwards }}$ & & & \\
$B_{8,200 \text { feet }}$ & & &
\end{tabular}




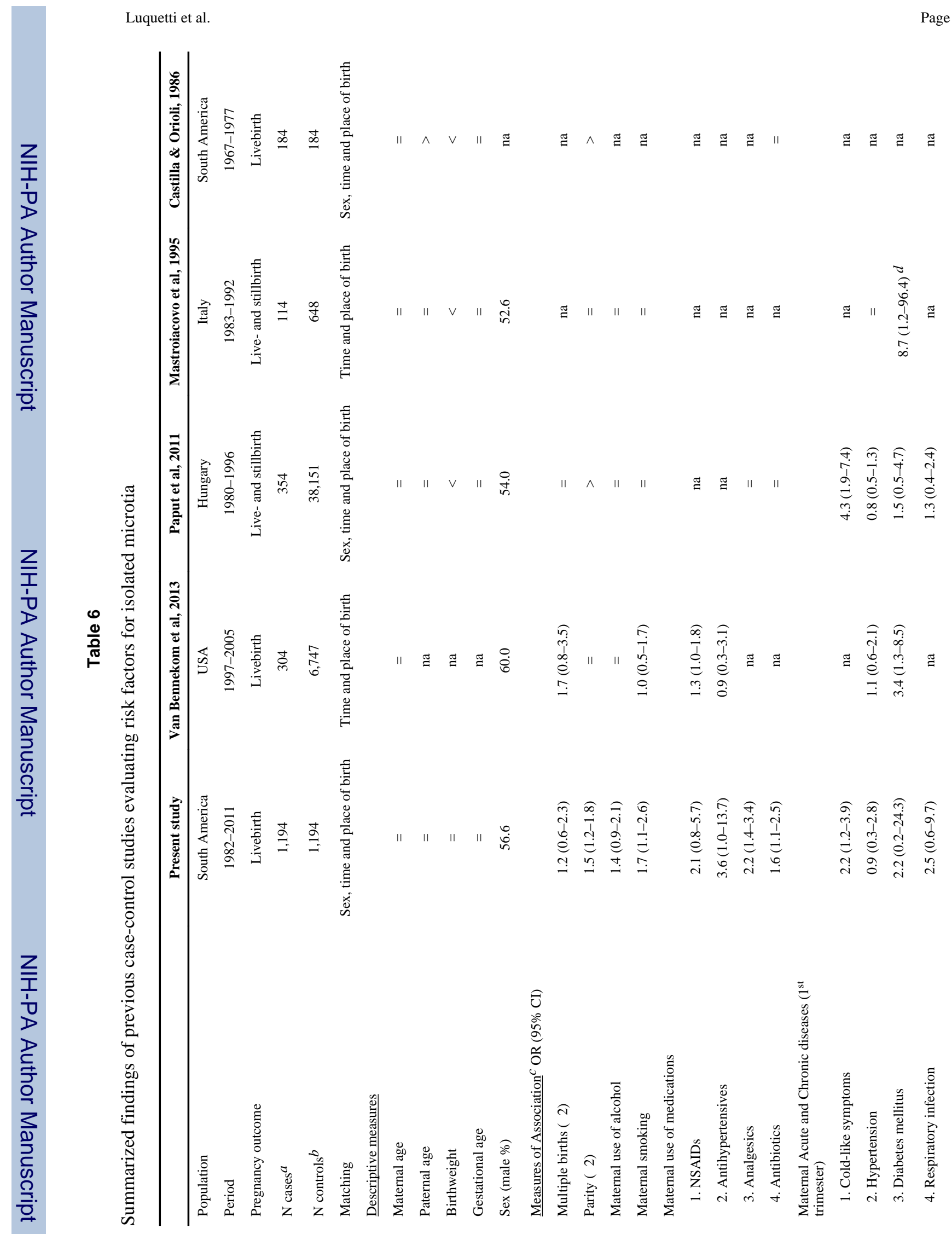

Birth Defects Res A Clin Mol Teratol. Author manuscript; available in PMC 2014 November 01. 
Luquetti et al.

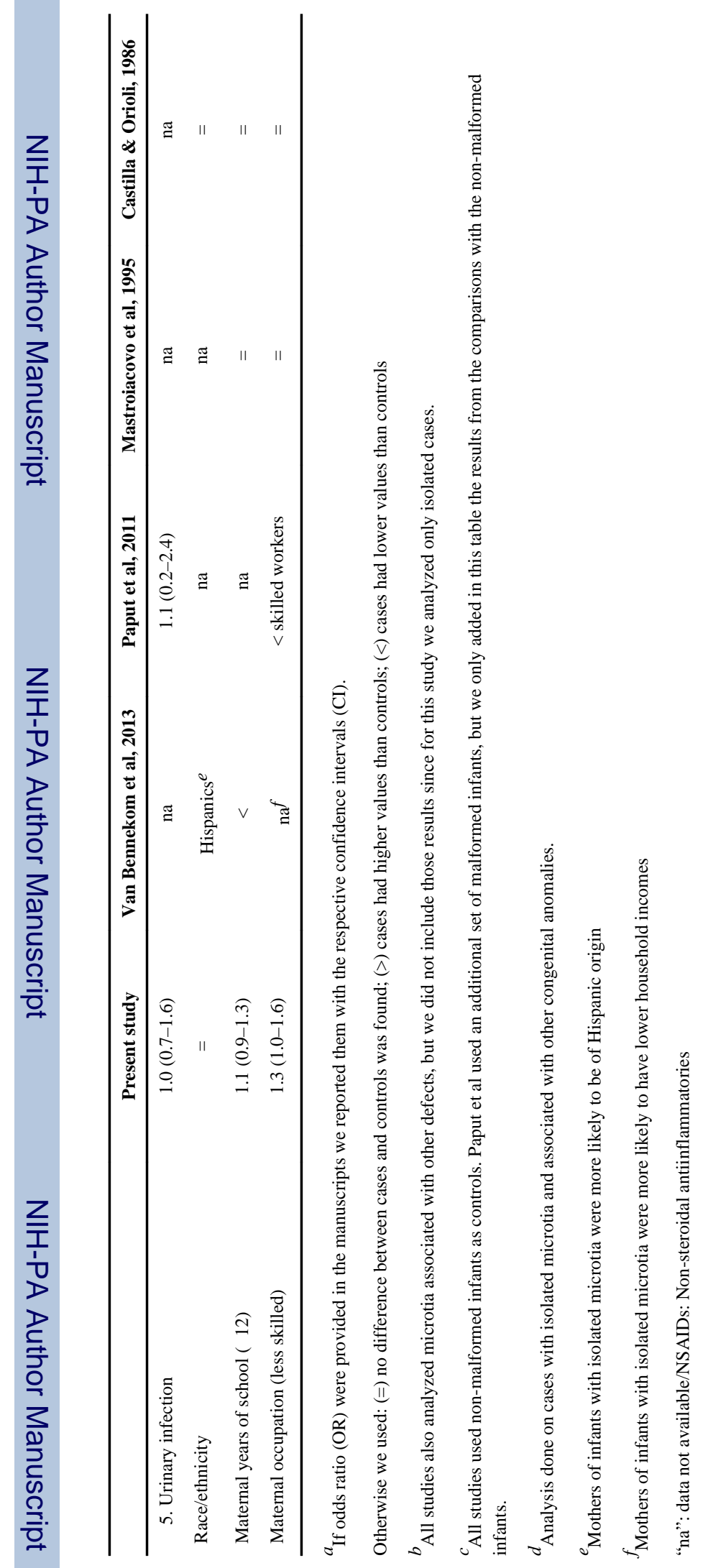

Birth Defects Res A Clin Mol Teratol. Author manuscript; available in PMC 2014 November 01. 